\title{
Contemporary issues and new challenges in chronic kidney disease amongst people living with HIV
}

Jack Edward Heron', Corinne Isnard Bagnis ${ }^{2}$ and David M. Gracey ${ }^{1,3^{*}}$

\begin{abstract}
Chronic kidney disease (CKD) is a comorbidity of major clinical significance amongst people living with HIV (PLWHIV) and is associated with significant morbidity and mortality. The prevalence of CKD is rising, despite the widespread use of antiretroviral therapy (ART) and is increasingly related to prevalent non-infectious comorbidities (NICMs) and antiretroviral toxicity. There are great disparities evident, with the highest prevalence of CKD among PLWHIV seen in the African continent. The aetiology of kidney disease amongst PLWHIV includes HIV-related diseases, such as classic HIV-associated nephropathy or immune complex disease, CKD related to NICMs and CKD from antiretroviral toxicity. CKD, once established, is often relentlessly progressive and can lead to end-stage renal disease (ESRD). Identifying patients with risk factors for CKD, and appropriate screening for the early detection of CKD are vital to improve patient outcomes. Adherence to screening guidelines is variable, and often poor. The progression of CKD may be slowed with certain clinical interventions; however, data derived from studies involving PLWHIV with CKD are sparse and this represent an important area for future research. The control of blood pressure using angiotensin converting enzyme inhibitors and angiotensin receptor blockers, in particular, in the setting of proteinuria, likely slows the progression of CKD among PLWHIV. The cohort of PLWHIV is facing new challenges in regards to polypharmacy, drug-drug interactions and adverse drug reactions. The potential nephrotoxicity of ART is important, particularly as cumulative ART exposure increases as the cohort of PLWHIV ages. The number of PLWHIV with ESRD is increasing. PLWHIV should not be denied access to renal replacement therapy, either dialysis or kidney transplantation, based on their HIV status. Kidney transplantation amongst PLWHIV is successful and associated with an improved prognosis compared to remaining on dialysis. As the cohort of PLWHIV ages, comorbidity increases and CKD becomes more prevalent; models of care need to evolve to meet the new and changing chronic healthcare needs of these patients.
\end{abstract}

Keywords: HIV, Chronic kidney disease, Renal failure, Anti-retroviral therapy, Screening

\section{Introduction}

Chronic kidney disease (CKD) is one of the most important non-infectious comorbidities (NICMs) seen in people living with HIV (PLWHIV), both in developed countries and in resource-poor settings [1,2]. The prevalence of CKD in PLWHIV continues to increase, despite

*Correspondence: David.Gracey@health.nsw.gov.au

${ }^{1}$ Department of Renal Medicine, Royal Prince Alfred Hospital, Camperdown, NSW, Australia

Full list of author information is available at the end of the article highly effective antiretroviral therapy (ART) [3]. While it has long been recognised that HIV infection is a risk factor for CKD, it is important to note that the pattern of kidney disease affecting PLWHIV has changed [4]. Rather than the previously seen HIV-associated renal conditions, or acute kidney injury (AKI) related to illnesses such as opportunistic infections, CKD now is often related to NICMs, particularly diabetes and hypertension [5]. As well, great disparities are evident, with most HIV infections occurring in minorities and in those in resource poor settings, or of African descent 
[6]. Long-term exposure to ART in an ageing cohort of PLWHIV contributes to the burden of renal disease [7]. These changes have led to new considerations in PLWHIV, including models of care, access to care in resource-limited settings, polypharmacy and geriatricspecific considerations [8]. With the increasing burden of renal disease seen in this patient group, the increasing numbers of PLWHIV requiring dialysis or kidney transplantation deserve special consideration [9]. This review was undertaken to assess the contemporary issues concerning CKD in PLWHIV and to focus on the challenges arising in the delivery of optimal care.

CKD is an important consideration in PLWHIV, both because of its increasing prevalence, and because of its well-documented adverse effects on patient morbidity and mortality [10]. Once established, CKD usually progresses, and may result in end-stage renal disease (ESRD), where a patient becomes dependent on dialysis or kidney transplantation [11]. The progression of CKD may be slowed with clinical interventions, such as weight loss, blood pressure management and treatment of dyslipidaemia or hyperglycaemia [12]. There are few specific data concerning the benefits of these strategies in PLWHIV, and interventional trials of these approaches are required. It may be that guidelines for CKD in patients with HIV need to be different than those in the general population. Also, CKD is associated with much comorbidity, the most important being cardiovascular disease (CVD), which may impact quality of life and survival $[13,14]$. In the general population, strategies for the early detection and prompt management of risk factors associated with CKD, have been shown to be beneficial in improving outcomes and preventing the development of CKD [15]. It is assumed that these same benefits would be seen in PLWHIV [16]. Strategies for the prevention of CKD and for the early detection of CKD amongst PLWHIV are a key concern. Studies have demonstrated that PLWHIV are less likely to receive aspirin for primary cardiovascular disease prevention, and that PLWHIV are less likely to achieve lipid-lowering targets on therapy, when compared to their uninfected counterparts [17]. The relative clinical contributions of the HIV itself, of the prolonged exposure to ART and of clinical risk factors, such as ageing, and NICMs are a difficult balance [18].

\section{Epidemiology of CKD in PLWHIV}

PLWHIV have a higher risk of developing CKD than in the general population. As well, in PLWHIV who are diagnosed with CKD, there is a 2 to 20 -fold greater chance of developing ESRD, compared to the general population $[19,20]$. This may be explained by the preponderance of risk factors for renal disease in this population; both related to the HIV-itself, as well as adverse effects of ART and comorbid conditions. CKD is also associated with increased hospital admissions, particularly in older patients and those with comorbid CVD [21]. World-wide, access to treatment for ESRD is an increasing concern, with CKD moving from the 27th to the 18th leading global cause of death in the past 20 years. The increase in importance of CKD as a global killer was second only to HIV [18]. Concurrently, there has also been a large increase in NICMs. There is overlap in the comorbidities observed with both CKD and HIV, and globally the increase in conditions, such as diabetes and hypertension, are important considerations in the management of both conditions [22, 23].

CKD is seen in PLWHIV with variable prevalence, depending on geographical location. Different formulas used to estimate renal function and different definitions of CKD between studies may also have a significant effect on estimates [24]. A global prevalence of CKD of $6.4 \%$ in PLWHIV using the Modification of Diet in Renal Disease (MDRD) formula, or $4.8 \%$ using the Chronic Kidney Disease Epidemiology Collaboration (CKD-EPI) formula, has been reported in a systematic review of studies from 60 countries world-wide; however, the African continent demonstrated the highest prevalence of CKD with $7.9 \%$ of PLWHIV affected, according to the MDRD formula [17]. Some studies have reported a much higher prevalence of CKD within Africa, with $44.4 \%$ affected by CKD in Cameroon using the CKD-EPI formula [25].

The higher prevalence of CKD in PLWHIV in Africa may be explained by the 18 to 50 -fold higher risk in those of African descent world-wide developing HIVrelated ESRD compared to Caucasians [26, 27]. The susceptibility to the development of kidney disease is primarily due to genetic factors [28]. Black African PLWHIV in the Western and Southern African continent are likely to carry genetic polymorphisms linked to an aggressive form of HIV-associated nephropathy (HIVAN). More recently, these polymorphisms have also been linked to susceptibility to a wider range of renal conditions, such as hypertension-related renal disease and Focal Segmental Glomerulosclerosis (FSGS) in HIV-negative individuals $[28,29]$. The apolipoprotein-1 (APOL-1) gene risk alleles G1 and G2, located on chromosome 22, have been strongly associated with the development of HIVAN; in fact, it is possible that these alleles are pre-requisites for its development [30]. The presence of APOL-1 risk alleles also predicts a more rapid progression of $C K D$, regardless of the underlying renal histopathology [28]. APOL-1 risk alleles are found in $70-80 \%$ of persons of African origin. The distribution of APOL-1 variants is closely associated with the prevalence of Trypanosomal infection; African nations with high frequencies of APOL1 risk alleles also have 
high rates of Trypanosomal infection, suggesting that these alleles underwent positive selection as a defense against infection [28].

Whilst accounting for much of the observed difference in the prevalence of CKD among PLWHIV, other factors contribute, including environmental factors and access to healthcare [31].

The prevalence of NICMs is significantly associated with the prevalence of CKD; the higher the prevalence of NICMs, the higher the prevalence of CKD [18, 32]. However, the increased susceptibility to CKD is more complex, with a contribution of traditional and HIVspecific risk factors for kidney disease [32]. As shown in Table 1, traditional risk factors for CKD include age, diabetes, hypertension, obesity, a history of AKI and cigarette smoking. Importantly, a large proportion of cases of ESRD in PLWHIV may be prevented with interventions to traditional risk factors [32, 33]. As well, HIV-related risk factors include HIV-viral replication, CD4 count nadir, Hepatitis C (HCV) co-infection and ART [34].

It can be seen that CKD in PLWHIV represents an immense global problem and has significant implications for healthcare systems [18]. The potential to prevent CKD and ESRF in PLWHIV highlights the importance of screening for, and timely management of, risk factors for CKD, as well as the early detection and management of those with established CKD. Many HIV care providers are not currently designed for such interventions, with the primary focus of many clinics being provision of ART and monitoring of HIV-specific indicators [35].

\begin{tabular}{l} 
Table $\mathbf{1}$ Traditional and HIV-associated risk factors \\
for kidney disease \\
\hline Traditional risk factors \\
Age \\
Ethnicity \\
Socioeconomic factors \\
Diabetes mellitus and obesity \\
Hypertension \\
Tobacco misuse \\
HIV-associated risk factors \\
History of recurrent acute kidney injury \\
HIV viral replication \\
Nadir CD4+ T cell count \\
APOL 1 gene risk alleles \\
Anti-retroviral therapy \\
IIlicit drug use \\
Coinfections, esp. Hepatitis B and C
\end{tabular}

\section{Detection of CKD}

Clinically, CKD is often asymptomatic and is found on routine screening [36]. Guidelines recommend that PLWHIV be screened regularly for CKD to allow for its early detection and management [34, 37, 38]. PLWHIV who are selected for CKD screening, in addition to a full clinical assessment for risk factors for renal disease and a measurement of their blood pressure, should have a urine test for protein and a blood test for serum creatinine to estimate their renal function [39]. It is recommended that PLWHIV have their GFR estimated at least every 6 months and should have either a urinalysis or a quantitative assessment of their urinary protein excretion at least annually. As well, those whose eGFR has declined by $25 \%$ or more, or to a level below $60 \mathrm{~mL} / \mathrm{min}$ per $1.73 \mathrm{~m}^{2}$, or who have protein excretion of over $300 \mathrm{mg} / \mathrm{day}$, should be referred for evaluation by a Nephrologist [37]. PLWHIV who are found to have haematuria with any level of proteinuria, or with an abnormal eGFR, should also be referred for assessment. In PLWHIV receiving TDF, more frequent screening for CKD is also recommended, including monitoring the serum phosphate [47]. Adherence to accepted guidelines for screening for CKD in PLWHIV is variable. Current screening practices fall short of suggested guidelines [40-42].

Clinical risk scores for CKD in PLWHIV have also been developed. These scores may be used to determine an individual's risk of developing CKD, based on known clinical risk factors for CKD, to grade an individual's risk of developing CKD. These scores may be useful in clinical decision making, particularly in guiding selection of ART in those at risk [43-45].

The measurement of renal function, or the glomerular filtration rate (GFR), is complex and the most commonly used methods are imperfect [46]. The GFR is usually estimated from the measurement of serum creatinine (eGFR). Creatinine is derived from the metabolism of creatine in the skeletal muscle, and from dietary meat intake. It is unreliable at extremes of body mass index, and may also be influenced by other factors, such as diet and concurrent medications; including some ART [24]. In using the serum creatinine to measure the GFR, an estimation equation is used. Commonly used methods include the Cockcroft-Gault equation, the MDRD formula and the CKD-EPI formula [39]. Because of the effect of skeletal muscle mass on serum creatinine, in elderly individuals with low muscle mass, the renal function may be over-estimated, with important implications for drug dosing [47]. Many different studies have evaluated the performance of these methods to estimate renal function in PLWHIV; it seems likely that the CKD-EPI formula is superior to other equations for estimating the 
GFR [48]. These methods provide results that are clinically useful in PLWHIV [49].

Other more accurate techniques for the measurement of renal function are available; however, these are more complex, expensive, and rarely used outside the setting of clinical trials. A 24-h urine collection can estimate an individual's creatinine clearance $(\mathrm{CrCl})$; this technique may be useful when determining appropriate drug doses for renally-excreted medications. Other measurements, such as the iohexol clearance, remain accurate even in PLWHIV who are receiving ART known to affect the renal handing of creatinine. In the research setting several molecules, such as cystatin $\mathrm{C}$, have also been investigated as potential markers of renal function $[50,51]$. Cystain $\mathrm{C}$ and other specific markers of renal function may be considered for use in situations where the serum creatinine is likely to be unreliable, such as in those individuals with extreme body mass indices, or in those on ART which may affect the excretion of creatinine. Cystain $\mathrm{C}$ can be influenced by factors such as inflammation, and the iohexol clearance remains the gold standard for measurement of renal function [52]. In resource limited settings, measurement of renal function may not be performed as part of routine assessments in PLWHIV [53]. Despite this, there is evidence to suggest that ART can be delivered safely without laboratory monitoring in subSaharan Africa [54].

Proteinuria may be quantitated with a urinary albumin:creatinine ratio (uACR), or a urinary protein:creatinine ratio. (UPCR) In PLWHIV on TDF a uPCR is preferred, instead of the uACR, which primarily detects urinary albumin, rather than other proteins. The tubular proteinuria seen with TDF toxicity is usually comprised of proteins other than albumin [55]. Both the uACR and uPCR may be used simultaneously to attempt to determine the aetiology of proteinuria in a patient treated with TDF [56]. Other urinary molecules, such as retinol binding protein and $\beta-2$ microglobulin, have also been used as potential biomarkers of renal tubular function; mainly in clinical trials [57].

\section{Causes of renal disease in PLWHIV}

As discussed in more detail below; the aetiology of CKD in PLWHIV may be related to the HIV-infection and associated viral replication itself or, more commonly, be due to manifestations of a patient's NICMs, or from side effects of ART [58]. A classification system of CKD in PLWHIV based on the dominant tissue compartment affected in the kidney may be useful, as shown in Table 2 [59]. To differentiate with certainty between the wide-range of different renal pathologies that are possible in PLWHIV a renal biopsy is required, although, not always clinically available or indicated. The clinical
Table 2 Classification of HIV associated renal pathology based on tissue compartment affected

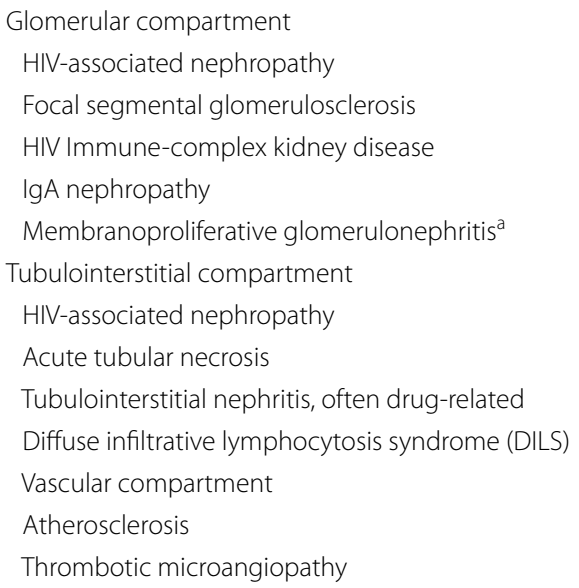

a Seen with hepatitis $\mathrm{C}$ co-infection

risks of performing a renal biopsy must also be considered [60]. As well, even with a renal biopsy, it can be difficult to attribute the causation of HIV in the pathological changes demonstrated [61].

\section{HIV-related kidney disease HIV-associated nephropathy}

Classic HIVAN manifests as a collapsing glomerulopathy with hypertrophy and hyperplasia of the overlying glomerular epithelial cells and associated prominent tubulointerstitial changes, including tubular microcysts and damage [62]. Classic HIVAN is strongly associated with the APOL-1 risk allele. Clinically, HIVAN is usually seen as a late complication of chronic HIV-infection, in patients with advanced immunocompromise. Cases of HIVAN have also been described during primary HIV infection with HIV, although, this is less common [63]. HIVAN usually presents with nephrotic-range proteinuria and progresses rapidly to ESRF. The kidneys may appear enlarged and echogenic on renal tract ultrasound [64]. Guidelines suggest the prompt commencement of ART in HIVAN $[34,37]$. The choice and dose of ART may be affected by the presence of HIVAN [62]. Corticosteroids have also been used; however, their role is less clear, and their use can be associated with a wide-range of sideeffects [65]. Angiotensin converting enzyme inhibitors (ACEi) and angiotensin receptor blockers (ARBs) may also be used.

Non-collapsing FSGS is now more commonly seen than classic HIVAN at renal biopsy [5, 64, 66]. In these patients, the viral load is usually undetectable and they are usually receiving ART. The histological findings may be difficult to distinguish from secondary FSGS. 
Causality is presumed to be related to HIV when no other secondary cause of FSGS is demonstrated. Effacement of the foot processes may been seen in both the classic collapsing and in the non-collapsing form; although, it is usually less prominent in those with the non-collapsing form [64]. Treatment of non-classic FSGS is usually with ACEi or ARBs; most of these patients are already receiving ART [67].

\section{HIV immune complex kidney disease}

Numerous forms of immune complex kidney disease may also be seen in PLWHIV. The term HIV immune complex kidney disease (HIVICK) is used to describe these conditions; however, because of the lack of certainty regarding causality of HIV and because of the heterogeneous nature of these conditions, a specific description of the pattern of immune complex deposition in the setting of HIV may be preferred $[59,68]$. These conditions include a lupus-like nephritis with negative autoimmune serologies and no other clinical signs of lupus [69]. As well, IgA nephropathy, membranous and membranoproliferative disease have all been described [70, 71]. Membranoproliferative glomerulonephritis may be seen in PLWHIV who are co-infected with hepatitis $C$ virus $[72,73]$. The deposition of IgA directed against HIV antigens has been described [70]. Clinically, these conditions have heterogeneous presentations; there may be microhaematuria, a variable degree of proteinuria and impairment of renal function. Immune complex disease benefits from ART and the prognosis appears to be favourable, compared to HIVAN. Consideration of the type and dose of ART used is important [74, 75].

\section{Tubulointerstitial conditions}

Less commonly, the tubulointerstitium may be involved in an abnormal immune response to HIV. Diffuse infiltrative lymphocytosis syndrome (DILS) is seen rarely in patients who develop a hyperimmune reaction against HIV, and can affect multiple organ systems [76]. DILS is managed by the initiation of ART, although, corticosteroids have also been used [77]. As well, the immune reconstitution inflammatory syndrome may be seen within the kidneys after the initiation of ART. This condition is usually managed by treatment directed to the specific pathogen underlying the response, although, corticosteroids may also be useful [78].

\section{Vascular conditions}

Progressive vascular disease may be seen in PLWHIV as a direct effect of the HIV on blood vessels within the kidney and is associated with dyslipidaemia and chronic inflammation [79]. This atypical atherosclerosis may be seen as a result of pathological lipid metabolism in the setting of an abnormal immune response [80]. This process is usually seen those with a high burden of risk factors for arteriosclerosis [81]. Abnormal carotid intimal-media thickness has been demonstrated in ARTnaïve children without additional risk factors [82]. Management is focused on modifiable risk factors. Type of ART is also an important consideration [14].

Thrombotic microangiopathy is now seen uncommonly; it is as a result of endothelial dysregulation. The condition manifests clinically with thrombocytopaenia, a microangiopathic anaemia and multisystem organ dysfunction, including AKI [83]. It is usually seen in those with high-level viral replication, not on ART. Treatment of this condition may include commencement of ART, plasma exchange and other immunosuppressive agents [84].

\section{CKD related to viral coinfections}

Hepatitis $\mathrm{C}$ and $\mathrm{B}$ (HCV, HBV) are the two most common coinfections seen in PLWHIV [85]. Both HCV and $\mathrm{HBV}$ are associated with CKD, and both may cause infection-associated glomerulonephritis [86]. This can lead to a challenging differential diagnosis of CKD in this population [87]. Worldwide, around 25-30\% of PLWHIV are coinfected with HCV and around $5-10 \%$ of those with HCV are coinfected with HIV [87]. In CKD with both $\mathrm{HCV}$ and $\mathrm{HBV}$ coinfection the management is directed at control of viral replication of both conditions. For HCV, direct-acting antivirals (DAA) have revolutionised the treatment of $\mathrm{HCV}$, with selected regimens demonstrating cure in over $95 \%$ of $\mathrm{HIV} / \mathrm{HCV}$ coinfected individuals using short treatment durations of 8-12 weeks [88]. For HCV/HIV coinfection regression of renal lesions has been seen with successful anti-viral management of both conditions [87].

\section{CKD related to non-infectious co-morbidities}

As in the general population, the commonest causes of CKD in PLWHIV are related to NICMs [89]. Hypertension, vascular disease and diabetes are most important causes of CKD in this group [90, 91]. HIV is associated with an increased risk of type 2 diabetes in most series; it is reported to be around four times more prevalent than in the general population [92, 93]. Type 2 diabetes has a greater prevalence and poorer treatment outcomes in PLWHIV compared to the general population [94]. As well, HIV is associated with progressive diabetic nephropathy in animal models [95]. Similarly, hypertension represents a major clinical problem in PLWHIV; in resource-poor settings this hypertension is often recognised and untreated [96]. Secondary FSGS may be related to hypertension; however, there may also be overlap with an HIV-related effect on the glomerulus [96]. 
Management of these conditions is important to try and slow progression of CKD. Many HIV care services were not designed to address NICMs [97, 98]. The management of comorbidities was identified was a main challenge in meeting the needs of PLWHIV in Australia [99]. This challenge is even greater in resource-limited settings [100].

\section{Renal effects of ART}

Data suggest a role for specific ART medications in contributing to the risk of CKD in PLWHIV [101]. The risk of CKD relates not only to the use of specific ART medications, but also to an individual's comorbid conditions, and advancing age $[102,103]$. CKD and risk factors for the development of CKD effects the choice and dosing of ART [37]. The access to screening tests and the availability of ART may also effect which medications are used [104]. Guidelines recommend the immediate initiation of ART in those diagnosed with HIV. This results in improved life expectancy, with a longer cumulative exposure to ART medications [1]. ART is also important in reducing HIV-related kidney disease [58].

Antiretroviral agents can cause direct toxicity to the kidney, in particular, tubular dysfunction, interstitial nephritis and renal calculi [105]. Recurrent episodes of AKI are a known risk factor for the development of CKD [106]. The management of these conditions is usually supportive; assessment of the type of ART used in these situations are important considerations [107]. The effects of ART on the kidneys are discussed in more detail below.

\section{Tenofovir disoproxil fumarate}

TDF is widely prescribed and is a very effective antiretroviral agent. TDF is excreted by the kidneys. Dose adjustments are required in those with significant CKD [108]. TDF is associated with proximal renal tubular dysfunction, manifest primarily as non-nephrotic proteinuria and phosphaturia; around $1-2 \%$ of all patients on TDF will need to stop treatment because of tubulopathy. In cases of severe tubulopathy there may be severe biochemical abnormalities, such as those seen with the Fanconi syndrome, osteomalacia and acute kidney injury [109]. The Fanconi syndrome is uncommon, and includes renal glycosuria, aminoaciduria, phosphaturia and renal tubular acidosis.

TDF has also been associated with CKD [110].

The precise mechanisms of TDF-associated nephrotoxicity are complex; it is associated with acute tubular necrosis of proximal renal tubular cells and with abnormally enlarged mitochondrial within these cells [111]. In experimental models, tenofovir has been shown to accumulate within tubular cells and induce mitochondrial toxicity [112]. Genetic polymorphisms in proximal renal tubular transporters may account for individual susceptibility to these effects [113]. Risk factors for TDF-nephrotoxicity include increased age, lower baseline renal function, duration of exposure and the concurrent use of ritonavir-boosted protease inhibitors (PIr) [106, 114, 115]. The effect of cumulative exposure to TDF appears important, with each year of TDF use associated with a $14-33 \%$ increase in the risk of declining kidney function $[115,116]$.

The pharmacoenhancer Cobicistat (COBI) has been shown to increase an individual's TDF exposure, and may increase the risk of TDF-associated nephrotoxicity [113]. TDF levels may also be increased by several other drug-drug interactions, including with non-steroidal anti-inflammatory agents and the antiviral agent ledipasvir (ref) [113].

It is recommended that PLWHIV be evaluated for their risk of CKD before commencing ART and that those on TDF should be screened regularly for the development of proximal renal tubulopathy, which is often asymptomatic [38]. It is recommended that TDF be replaced by a non-tenofovir drug, or by the newer Tenofovir alafenamide (TAF), if there is documented proteinuria, persistent hypophosphatemia, a progressive decline in GFR with no other apparent cause, or osteopenia or osteoporosis in the setting of a high urinary phosphate excretion [37]. It is also recommended that TDF be replaced, or not used, in PLWHIV with significant proteinuria from any cause, a declining GFR, or a high risk of CKD [37]. The effect of switching off TDF on clinical parameters is variable, with some patients exhibiting progressive CKD, despite the cessation of TDF [113].

In addition to its use in ART, TDF combined with emtricitabine (FTC) may also be used for pre-exposure prophylaxis (PrEP); either daily or on-demand $[117,118]$. Both dosing strategies are very effective for the prevention of HIV-infection [119]. Toxicity associated with the use of TDF/FTC remains a consideration, although, its safety profile appears much more favourable amongst the HIV-uninfected population [120]. Indeed, in a recent meta-analysis of adverse effects of TDF/FTC for PrEP, there were no significant differences in serious adverse events between the TDF/FTC group and the placebo arm of these studies [121]. Risk factors for TDF toxicity appear similar both in PLWHIV and those on PrEP; recommendations for screening and monitoring are also similar in both groups (ref) [113]. There are; though, few options for PrEP in individuals with significant CKD; the newer pro-drug TAF may be a safe and effective option [107]. Novel agents and alternative delivery methods are currently under development, and may also be useful for PrEP amongst those with significant CKD [122]. 


\section{Tenofovir alafenamide (TAF)}

TAF is a pro-drug of TDF, which reaches a higher intracellular concentration in peripheral blood mononuclear cells than TDF, despite maintaining a much lower concentration in the plasma. TAF has been demonstrated to have minimal mitochondrial toxicity in vivo. To date, clinical studies of TAF have demonstrated a much more favourable renal and bone side-effect profile [123]. Possible TAF-associated nephrotoxicity has been reported, although, causation was difficult to establish [124]. Fanconi syndrome has also been reported in patients receiving TAF for the treatment of HIV infection, although causation is not definitive [125]. TAF has been used in PLWHIV and in the general population for the treatment of chronic hepatitis B. TAF is recommended as an option for treatment for PLWHIV who develop TDF-related nephrotoxicity, and in those with significant proteinuria or renal impairment at baseline [123]. Switch studies from TDF to TAF suggest a potential reversion of renal toxicity [126]. No dose adjustment of TAF is required, even in PLWHIV with significant renal impairment. TAF is not recommended for use in those with ESRD, although, it has been safely used previously in patients on haemodialysis. Longer-term safety data for this novel agent are emerging. No specific screening tests are recommended in addition to the usual health checks in PLWHIV receiving TAF [123]. Regardless of type of ART used, all PLWHIV should be assessed regularly for their risk of CKD.

\section{Protease inhibitors}

Protease inhibitors are now used less commonly with the advent of newer ART [127]. The protease inhibitors indinavir (IDV), lopinavir (LPV) and atazanavir (ATV) have been associated with nephrolithiasis, which can manifest as crystalluria, haematuria and loin pain; they may be associated with renal calculi and acute kidney injury [128]. These effects may mandate the discontinuation of these agents [37]. In addition to the withdrawal of offending agents, a specialist assessment for a stoneforming tendency should be undertaken; there is a high recurrence rate of renal stone disease in PLWHIV, often thought to be secondary to metabolic complications.

Cohort studies have also found that several PIrs are associated with the risk of CKD [105]. However, the relative contribution of Pis to progressive CKD has been questioned, particularly in those concurrently receiving TDF [129]. In the D:A:D study, including PLWHIV not receiving TDF, the cumulative use of $\mathrm{ATV} / \mathrm{r}$ and $\mathrm{LPV} / \mathrm{r}$ was associated with a higher relative risk of CKD, an increase of $22 \%$ and $13 \%$, respectively [110]. There is some evidence to suggest that these changes in renal function may largely be determined by the effects of
Ritonavir (RTV) on tubular creatinine transport, rather representing a direct nephrotoxic effect of either ATV or LPV [110, 130]. The reduction in eGFR observed with these agents appears reversible upon their cessation, and does not seem to be associated with advanced CKD or ESRD [110]. Data concerning the association of DRV with CKD is less robust [110]. The use of PIrs is also a known risk factor for TDF-nephrotoxicity. PIs have also been associated with a variety of metabolic adverse effects, including weight gain, which may also predispose to the development of CKD $[114,131]$.

\section{Cobicistat}

COBI is a pharmacoenhancer and is not nephrotoxic; it is a potent inhibitor of cytochrome 3A (CYP3A), and has no inherent anti-HIV effect. It is used to inhibit the metabolism of other ART to allow them to be dosed in single-daily combination preparations [130]. COBI inhibits the multidrug and toxin extruder protein (MATE-1) in the proximal renal tubule, inhibiting the excretion of creatinine by the kidney, without effecting the actual GFR. The increase in the serum creatinine observed is seen early after commencing therapy, and is not progressive; a continued decline in renal function would raise concerns of a different cause of renal dysfunction [132]. The measurement of GFR in patients on COBI is complicated, as are drug-drug interactions [37]. More recently, oncedaily combination therapies, such as Bictegravir (BIC), have become available without need for a pharmacological booster agent [133].

\section{Integrase inhibitors}

The integrase strand transfer inhibitors (INSTIs) include raltegravir (RAL), dolutegravir (DTG) elvitegravir (EVG) and BIC. Weight gain has been reported as a side-effect of INSTIs; however, it is not clear if this is a medicationspecific, or a class effect [134]. RAL has been reported to reduce renal function; the mechanism underlying this observation is unclear; however, it does not seem to be related to the tubular excretion of creatinine. Small reductions in renal function were been observed in clinical trials of RAL. Additionally, an association with rhabdomyolysis is possible [130]. Very few adverse renal effects have been reported with EVG; it is usually given with a second agent, such as COBI, to boosts its levels and allow once-daily administration; this may affect the serum creatinine. BIC, similarly, has been associated with very few renal side-effects; no boosting agent is required. Whilst not nephrotoxic, DTG has been associated with an increase in the serum creatinine concentration by inhibiting the organic cation transporter (OCT-2) in the proximal renal tubule, without altering the actual GFR [135]. This can affect the estimation of GFR, with 
an apparent reduction expected. In clinical trials, a modest, non-progressive, increase in the serum creatinine was observed, usually within the first $1-2$ weeks after commencing therapy [130]. In the SPRING-2 study after 48 weeks of follow up, the mean $\mathrm{CrCl}$ decreased by $16.5 \mathrm{~mL} / \mathrm{min}$ in the DTG group, compared to $5.4 \mathrm{~mL} / \mathrm{min}$ in the RAL group [136]. Similar to COBI, a new set-point for renal function is usually apparent soon after commencing therapy; a continuing decline in renal function would raise concerns of a different cause for renal dysfunction [37]. The OCT-2 co-transporter is also responsible for the renal excretion of some medications, including Metformin, and this is a clinical consideration in diabetics commenced on DTG [135]. DTG does not require dose adjustment in CKD [130].

\section{An approach to the treatment of renal disease}

PLWHIV who have CKD and albuminuria are at particular risk of morbidity and mortality [137]. These individuals should be assessed for reversible factors placing them at risk of progression of renal disease; risk factors should be addressed early. Attention to blood pressure control, treatment of hyperglycaemia, hyperlipidaemia and lifestyle factors, such as weight loss and smoking cessation, are important $[37,138]$. Pharmacological control of hypertension with an ACE-i or an ARB should be commenced, particularly if there is proteinuria [139]. The renal function and serum potassium should be monitored in people who commence treatment with these agents. A blood pressure target of under $130 / 80 \mathrm{mmHg}$ is usually appropriate [140]. Other reversible causes for renal impairment should be sought and underlying renal conditions, such as HIVAN, should be excluded. PLWHIV with CKD or ESRD should be commenced on ART, which improves outcomes. Dose adjustment of medications excreted by the kidneys should be undertaken, and the use of nephrotoxic agents should be avoided [37]. The management of PLWHIV with CKD is usually undertaken in consultation with a Nephrologist.

\section{Polypharmacy}

Polypharmacy and the risks of drug-drug interactions are high in PLWHIV, particularly in the older patient group [141]. These concerns may partly explain the lower rate of non-ART medications used for prevention and treatment of CVD in PLWHIV. This is particularly relevant given the ageing of the PLWHIV cohort, and the associated increasing burden of NICMs [142]. Polypharmacy is also associated with adverse drug events, interactions and poor adherence. Adverse drug reactions are much more frequently seen in PLWHIV, compared to the general population [102]. In recent times, there has been a move to simpler two-drug ART regimens in an attempt to simplify ART and improve tolerability [143].

\section{Dialysis}

The number of PLWHIV on dialysis is increasing with the improved survival seen in this group [67]. Access to dialysis should not be impeded because of an individual's serological status; particularly taking into account the similar life expectancy of a PLWHIV on ART, compared to that of the general population [144]. The oneyear survival rate of PLWHIV on dialysis has improved, although, the rate remains inferior to that of the general population. Evidence suggests similar outcomes between haemodialysis and peritoneal dialysis in PLWHIV [145]. Drug dosing and comorbidities are major issues in this group [67].

\section{Renal transplantation}

Improvements in the long-term prognosis of PLWHIV and studies demonstrating good outcomes with kidney transplantation in PLWHIV have prompted many transplant programs to offer kidney transplantation as standard therapy to those PLWHIV with ESRD as an alternative to remaining on dialysis [146]. Studies have demonstrated a better long-term prognosis in selected patients with well-controlled HIV, compared to remaining on the kidney transplant waitlist. The optimal approach for kidney transplantation in PLWHIV has emerged as an important consideration; particularly, immunosuppressant protocols and infection prophylaxis. As well, the potential for drug-drug interactions between immunosuppressants and ART is well recognised; particularly in those receiving CYP3A inhibitors, such as PIr, who receive Tacrolimus-based immunosuppression [147]. Those receiving PIr and Tacrolimus require a dramatic reduction in Tacrolimus doses to avoid supra-therapeutic Tacrolimus levels post-transplant; Tacrolimus is normally metabolised by CYP3A [148]. It is preferable to modify ART to avoid these drug-drug interactions, before kidney transplantation is undertaken [149]. An increase in the risk of acute rejection demonstrated in this group has meant that Tacrolimus-based immunosuppression is used preferentially, with some transplant centres also using additional induction therapy [150]. Despite the increased risk of acute kidney transplant rejection amongst PLWHIV, outcomes are similar to the non-infected population [151]. However, outcomes in individuals co-infected with hepatitis $\mathrm{C}$ remain inferior (ref) [149]. Kidney transplantation in PLWHIV has also been performed from both living and deceased HIV-positive donors, with good outcomes [152]. 


\section{Conclusions}

PLWHIV are at an increased risk of CKD, which is most often related to NICMs, such as diabetes and hypertension. NICMs are becoming increasingly prevalent as the cohort of PLWHIV ages. As a consequence, models of care need to evolve to meet the new and changing healthcare needs of PLWHIV. CKD in PLWHIV is associated with poorer clinical outcomes, including higher morbidity and mortality, and is strongly associated with CVD. Potentially nephrotoxic ART may be avoided if an individual is at high risk of CKD, or if there is established CKD. Regardless of the type of ART used, all PLWHIV are at risk for CKD and should be routinely screened for risk factors and the presence of CKD. Among PLWHIV who are at high risk of CKD, blood pressure control, treatment of hyperglycaemia, hyperlipidaemia and attention to lifestyle factors, such as weight loss and smoking cessation, are important. Control of established hypertension with an ACE-i or an ARB is indicated, particularly if there is proteinuria. These recommendations are based on evidence from studies in the general population, and further research is required to define the optimal strategies for the prevention and management of CKD among PLWHIV. The number of PLWHIV with ESRD is increasing worldwide; this group should not be denied renal replacement therapy, either dialysis or renal transplantation, based on their HIV status.

\begin{abstract}
Abbreviations
ACEi: Angiotensin converting enzyme inhibitor; APOL-1: Apolipoprotein-1; ARB: Angiotensin receptor blocker; ART: Antiretroviral therapy; ATV: Atazanavir; BIC: Bictegravir; CKD: Chronic kidney disease; COBI: Cobicistat; DTG: Dolutegravir; eGFR: Estimated glomerular filtration rate; EVG: Elvitegravir; DILS: Diffuse infiltrative lymphocytosis syndrome; ESRD: End-stage renal disease; FSGS: Focal segmental glomerulosclerosis; HIVAN: HIV-associated nephropathy; HIVICK: HIV immune complex kidney disease; IDV: Indinavir; INSTI: Integrase strand transfer inhibitors; LPV: Lopinavir; NICM: Non-infectious comorbidity; PLWHIV: People living with human immunodeficiency virus; RAL: Raltegravir; TAF: Tenofovir alafenamide; TDF: Tenofovir disoproxil fumarate; UACR: Urine albumin creatinine ratio; uPCR: Urine protein creatinine ratio.
\end{abstract}

\section{Acknowledgements}

We would like to acknowledge the people living with HIV who have participated in, and contributed to, the body of research referenced in this review.

\section{Authors' contributions}

DG and JH both wrote the first draft of the manuscript. CB reviewed and edited the manuscript. All authors read and approved the final manuscript.

\section{Funding}

No funding was received for the preparation of this manuscript.

Availability of data and materials

Not applicable.

Ethics approval and consent to participate

Not applicable.

\section{Consent for publication}

This manuscript is our original work. All authors have read the final version of the manuscript and have approved it for submission.

\section{Competing interests}

DG and CB have previously received honoraria from Gilead, BMS and ViiV. JH has previously received financial support for travel from Gilead. These payments have in no way influenced the content of this manuscript.

\section{Author details}

${ }^{1}$ Department of Renal Medicine, Royal Prince Alfred Hospital, Camperdown, NSW, Australia. ${ }^{2}$ Nephrology Department, Groupe Hospitalier Pitié-Salpêtrière, 47 Boulevard de l'Hôpital, 75013 Paris, France. ${ }^{3}$ Central Clinical School, The University of Sydney, Sydney, NSW, Australia.

Received: 28 October 2019 Accepted: 22 February 2020

Published online: 16 March 2020

References

1. Abraham AG, Althoff KN, Jing Y, Estrella MM, Kitahata MM, Wester CW, et al. End-stage renal disease among HIV-infected adults in North America. Clin Infect Dis. 2014;60(6):941-9.

2. Kalyesubula R, Hau JP, Asiki G, Ssebunya B, Kusemererwa S, Seeley J, et al. Impaired renal function in a rural Ugandan population cohort. Wellcome Open Res. 2018;3:149.

3. Schwartz EJ, Szczech LA, Ross MJ, Klotman ME, Winston JA, Klotman PE. Highly active antiretroviral therapy and the epidemic of HIV+ endstage renal disease. J Am Soc Nephrol. 2005;16(8):2412-20.

4. Rosenberg AZ, Naicker S, Winkler CA, Kopp JB. HIV-associated nephropathies: epidemiology, pathology, mechanisms and treatment. Nat Rev Nephrol. 2015;11(3):150.

5. Mallipattu SK, Salem F, Wyatt CM. The changing epidemiology of HIV-related chronic kidney disease in the era of antiretroviral therapy. Kidney Int. 2014;86(2):259-65.

6. Pellowski JA, Kalichman SC, Matthews KA, Adler N. A pandemic of the poor: social disadvantage and the US HIV epidemic. Am Psychol. 2013;68(4):197.

7. Gueler A, Moser A, Calmy A, Günthard HF, Bernasconi E, Furrer H, et al. Life expectancy in HIV-positive persons in Switzerland: matched comparison with general population. AIDS. 2017;31(3):427.

8. Phair J, Palella F. Renal disease in HIV infected Individuals. Current Opinion in HIV and AIDS. 2011;6(4):285.

9. Wyatt CM, Murphy B, editors. Kidney transplantation in HIV-infected patients. Seminars in dialysis. Wiley Online Library. 2005.

10. Post FA, Holt SG. Recent developments in HIV and the kidney. Curr Opin Infect Dis. 2009;22(1):43-8.

11. Abboud H, Henrich WL. Stage IV chronic kidney disease. N Engl J Med. 2010;362(1):56-65.

12. Henry TY. Progression of chronic renal failure. Arch Intern Med. 2003;163(12):1417-29.

13. Snyder JJ, Collins AJ. Association of preventive health care with atherosclerotic heart disease and mortality in CKD. J Am Soc Nephrol. 2009;20(7):1614-22

14. Boccara F. Cardiovascular health in an aging HIV population. AIDS. 2017;31:S157-63.

15. Schieppati A, Pisoni R, Remuzzi G. Pathophysiology and management of chronic kidney disease. In: Greenberg A, editor. Primer on kidney diseases. Philadelphia: Elsevier Saunders; 2005.

16. Jotwani V, Li Y, Grunfeld C, Choi Al, Shlipak MG. Risk factors for ESRD in HIV-infected individuals: traditional and HIV-related factors. Am J Kidney Dis. 2012;59(5):628-35.

17. Suchindran S, Regan S, Meigs JB, Grinspoon SK, Triant VA, editors. Aspirin use for primary and secondary prevention in human immunodeficiency virus (HIV)-infected and HIV-uninfected patients. Open forum infectious diseases. Oxford University Press; 2014.

18. Ekrikpo UE, Kengne AP, Bello AK, Effa EE, Noubiap JJ, Salako BL, et al. Chronic kidney disease in the global adult HIV-infected population: a systematic review and meta-analysis. PLoS ONE. 2018;13(4):e0195443. 
19. Lucas GM, Mehta SH, Atta MG, Kirk GD, Galai N, Vlahov D, et al. End-stage renal disease and chronic kidney disease in a cohort of African-American HIV-infected and at-risk HIV-seronegative participants followed between 1988 and 2004. AIDS. 2007;21(18):2435-43.

20. Bansi L, Hughes A, Bhagani S, Mackie NE, Leen C, Levy J, et al. Clinical epidemiology of HIV-associated end-stage renal failure in the UK. AIDS. 2009;23(18):2517-21.

21. Louis M, Cottenet J, Salmon-Rousseau A, Blot M, Bonnot P-H, Rebibou $\mathrm{J}-\mathrm{M}$, et al. Prevalence and incidence of kidney diseases leading to hospital admission in people living with HIV in France: an observational nationwide study. BMJ Open. 2019;9(5):e029211.

22. Xie Y, Bowe B, Mokdad AH, Xian H, Yan Y, Li T, et al. Analysis of the Global Burden of Disease study highlights the global, regional, and national trends of chronic kidney disease epidemiology from 1990 to 2016. Kidney Int. 2018;94(3):567-81.

23. Uwimana Nicol J, Rohwer A, Young T, Bavuma CM, Meerpohl JJ. Integrated models of care for diabetes and hypertension in low- and middle-income countries (LMICs): Protocol for a systematic review. Syst Rev. 2018;7(1):203.

24. Stevens LA, Coresh J, Greene T, Levey AS. Assessing kidney function-measured and estimated glomerular filtration rate. N Engl J Med. 2006;354(23):2473-83.

25. Patrice HM, Moussa O, François KF, Yacouba M, Hugo B, Ngahane M, et al. Prevalence and associated factors of chronic kidney disease among patients infected with human immunodeficiency virus in Cameroon. Iran J Kidney Dis. 2018;12(5):268-74.

26. Lucas GM, Lau B, Atta MG, Fine DM, Keruly J, Moore RD. Chronic kidney disease incidence, and progression to end-stage renal disease, in HIV-infected individuals: a tale of two races. J Infect Dis. 2008;197(11):1548-57.

27. National Institutes of Health. United States Renal Data System 2011 annual data report: atlas of chronic kidney disease and end-stage renal disease in the United States. National Institutes of Health: National Institute of Diabetes and Digestive and Kidney Diseases; 2011.

28. Dummer PD, Limou S, Rosenberg AZ, Heymann J, Nelson G, Winkler CA et al. editors. APOL1 kidney disease risk variants: an evolving landscape. Seminars in nephrology. Amsterdam: Elsevier; 2015

29. Freedman BI, Limou S, Ma L, Kopp JB. APOL1-associated nephropathy: a key contributor to racial disparities in CKD. Am J Kidney Dis. 2018;72(5):S8-16.

30. Behar DM, Kedem E, Rosset S, Haileselassie Y, Tzur S, Kra-Oz Z, et al. Absence of APOL1 risk variants protects against HIV-associated nephropathy in the Ethiopian population. Am J Nephrol. 2011;34(5):452-9.

31. Ying R, Granich RM, Gupta S, Williams BG. CD4 cell count: declining value for antiretroviral therapy eligibility. Clin Infect Dis. 2016;62(8):1022-8.

32. Althoff KN, Gebo KA, Moore RD, Boyd CM, Justice AC, Wong C, et al. Contributions of traditional and HIV-related risk factors on non-AIDSdefining cancer, myocardial infarction, and end-stage liver and renal diseases in adults with HIV in the USA and Canada: a collaboration of cohort studies. Lancet HIV. 2019;6(2):e93-104.

33. Estrella MM, Fine DM. Screening for chronic kidney disease in HIVinfected patients. Advances in chronic kidney disease. 2010;17(1):26-35.

34. Lucas GM, Ross MJ, Stock PG, Shlipak MG, Wyatt CM, Gupta SK, et al. Clinical practice guideline for the management of chronic kidney disease in patients infected with HIV: 2014 update by the HIV Medicine Association of the Infectious Diseases Society of America. Clin Infect Dis. 2014;59(9):e96-138

35. Weiss JJ, Osorio G, Ryan E, Marcus SM, Fishbein DA. Prevalence and patient awareness of medical comorbidities in an urban AIDS clinic. AIDS Patient Care STDs. 2010;24(1):39-48.

36. García-García G, Gutiérrez-Padilla AJ, Chávez-Iñiguez J, Pérez-Gómez HR, Mendoza-García M, Tonelli M. Identifying undetected cases of chronic kidney disease in Mexico. Targeting high-risk populations. Archiv Med Res. 2013:44(8):623-7.

37. European AIDS Clinical Society. European AIDS Clinical Society Guidelines Belgium2018 [Version 9.1]. http://www.eacsociety.org/files /2018_guidelines-9.1-english.pdf. Accessed 20 Nov 2019.

38. Holt SG, Gracey DM, Levy MT, Mudge DW, Irish AB, Walker RG, et al. A consensus statement on the renal monitoring of Australian patients receiving tenofovir based antiviral therapy for HIV/HBV infection. AIDS Res Therapy. 2014;11(1):35.

39. Levey A, Atkins R, Coresh J, Cohen E, Collins A, Eckardt K-U, et al. Chronic kidney disease as a global public health problem: approaches and initiatives - a position statement from Kidney Disease Improving Global Outcomes. Kidney Int. 2007;72(3):247-59.

40. Gracey D, Chan D, Bailey M, Richards D, Dalton B. Screening and management of renal disease in human immunodeficiency virus-infected patients in A ustralia. Intern Med J. 2013:43(4):410-6.

41. George S, McGrath N, Oni T. The association between a detectable HIV viral load and non-communicable diseases comorbidity in HIV positive adults on antiretroviral therapy in Western Cape, South Africa. BMC Infect Dis. 2019;19(1):348.

42. Achwoka D, Waruru A, Chen T-H, Masamaro K, Ngugi E, Kimani M, et al. Noncommunicable disease burden among HIV patients in care: a national retrospective longitudinal analysis of HIV-treatment outcomes in Kenya, 2003-2013. BMC Public Health. 2019;19(1):372.

43. Mocroft A, Lundgren JD, Ross M, Law M, Reiss P, Kirk O, et al. Development and validation of a risk score for chronic kidney disease in HIV infection using prospective cohort data from the D:A: D study. PLoS Med. 2015;12(3):e1001809.

44. Mocroft A, Lundgren J, Ross M, Law M, Reiss P, Kirk O, et al. A clinically useful risk-score for chronic kidney disease in HIV infection. J Int AIDS Soc. 2014;17(4 Suppl 3):19514.

45. Woolnough EL, Hoy JF, Cheng AC, Walker RG, Chrysostomou A, Woolley I, et al. Predictors of chronic kidney disease and utility of risk prediction scores in HIV-positive individuals. AIDS. 2018;32(13):1829-35.

46. Gansevoort RT, Bakker SJ, De Jong PE. Early detection of progressive chronic kidney disease: is it feasible? J Am Soc Nephrol. 2006;17(5):1218-20

47. Heymsfield SB, Arteaga C, McManus C, Smith J, Moffitt S. Measurement of muscle mass in humans: validity of the 24-hour urinary creatinine method. Am J Clin Nutr. 1983;37(3):478-94.

48. Bonjoch A, Bayés B, Riba J, Puig J, Estany C, Perez-Alvarez N, et al. Validation of estimated renal function measurements compared with the isotopic glomerular filtration rate in an HIV-infected cohort. Antiviral Res. 2010;88(3):347-54.

49. Barraclough $\mathrm{K}, \mathrm{Er}$ L, Ng F, Harris M, Montaner J, Levin A. A comparison of the predictive performance of different methods of kidney function estimation in a well-characterized HIV-infected population. Nephron Clin Pract. 2009;111(1):c39-48.

50. Stevens LA, Coresh J, Schmid CH, Feldman HI, Froissart M, Kusek J, et al. Estimating GFR using serum cystatin $C$ alone and in combination with serum creatinine: a pooled analysis of 3,418 individuals with CKD. Am J Kidney Dis. 2008;51(3):395-406.

51. Dharnidharka VR, Kwon C, Stevens G. Serum cystatin C is superior to serum creatinine as a marker of kidney function: a meta-analysis. Am J Kidney Dis. 2002;40(2):221-6.

52. Pasala S, Carmody JB. How to use... serum creatinine, cystatin $C$ and GFR. Arch Dis Child Educ Pract Ed. 2017;102(1):37-43.

53. Deckert A, Neuhann F, Klose C, Bruckner T, Beiersmann C, Haloka J, et al. Assessment of renal function in routine care of people living with HIV on ART in a resource-limited setting in urban Zambia. PLOS ONE. 2017;12(9):e0184766.

54. Team DT. Routine versus clinically driven laboratory monitoring of HIV antiretroviral therapy in Africa (DART): a randomised non-inferiority trial. Lancet. 2010;375(9709):123-31.

55. Peyriere H, Cournil A, Casanova M-L, Badiou S, Cristol J-P, Reynes J. Long-term follow-up of proteinuria and estimated glomerular filtration rate in HIV-infected patients with tubular proteinuria. PLOS ONE. 2015;10(11):e0142491.

56. Samarawickrama A, Cai M, Smith ER, Nambiar K, Sabin C, Fisher M, et al. Simultaneous measurement of urinary albumin and total protein may facilitate decision-making in HIV-infected patients with proteinuria. HIV Med. 2012;13(9):526-32.

57. del Palacio M, Romero S, Casado JL. The use of biomarkers for assessing HAART-associated renal toxicity in HIV-infected patients. Curr HIV Res. 2012;10(6):521-31.

58. Jotwani V, Atta MG, Estrella MM. Kidney disease in HIV: moving beyond HIV-associated nephropathy. J Am Soc Nephrol. 2017;28(11):3142-54. 
59. Swanepoel CR, Atta MG, D'Agati VD, Estrella MM, Fogo AB, Naicker S, et al. Kidney disease in the setting of HIV infection: conclusions from a Kidney Disease: improving Global Outcomes (KDIGO) Controversies Conference. Kidney Int. 2018;93(3):545-59.

60. Da Silva D, Gluz I, Kurz J, Thome G, Zancan R, Bringhenti R, et al. Multiple facets of HIV-associated renal disease. Brazil J Med Biol Res. 2016. https ://doi.org/10.1590/1414-431X20165176.

61. Ellis CL, editor HIV associated kidney diseases: Clarifying concordance between renal failure in HIV infection and histopathologic manifestations at kidney biopsy. Seminars in diagnostic pathology. Amsterdam: Elsevier; 2017

62. D'Agati V, Suh J-I, Carbone L, Cheng J-T, Appel G. Pathology of HIVassociated nephropathy: a detailed morphologic and comparative study. Kidney Int. 1989;35(6):1358-70.

63. De Laroche M, Desbuissons G, Rouvier P, Barin F, Deray G, Caumes E, et al. APOL1 variants may induce HIV-associated nephropathy during HIV primary infection. J Antimicrob Chemother. 2017;72(5):1539-41.

64. Wyatt CM, Klotman PE, D'Agati VD, editors. HIV-associated nephropathy: clinical presentation, pathology, and epidemiology in the era of antiretroviral therapy. Seminars in nephrology. Amsterdam: Elsevier; 2008.

65. Smith MC, Pawar R, Carey JT, Graham RC Jr, Jacobs GH, Menon A, et al. Effect of corticosteroid therapy on human immunodeficiency virusassociated nephropathy. Am J Med. 1994;97(2):145-51.

66. Berliner AR, Fine DM, Lucas GM, Rahman MH, Racusen LC, Scheel PJ, et al. Observations on a cohort of HIV-infected patients undergoing native renal biopsy. Am J Nephrol. 2008;28(3):478-86.

67. Naicker S, Rahmania S, Kopp JB. HIV and chronic kidney disease. Clin Nephrol. 2015;83(Suppl 1):S32

68. Kimmel PL, Phillips TM, Ferreira-Centeno A, Farkas-Szallasi T, Abraham AA, Garrett CT. HIV-associated immune-mediated renal disease. Kidney Int. 1993:44(6):1327-40

69. Haas M, Kaul S, Eustace JA. HIV-associated immune complex glomerulonephritis with "lupus-like" features: a clinicopathologic study of 14 cases. Kidney Int. 2005;67(4):1381-90.

70. Kimmel P, Phillips T, Ferreira-Centeno A, Farkas-Szallasi T, Abraham A, Garrett C. Brief report: idiotypic IgA nephropathy in patients with HIV infection. N Engl J Med. 1992;327:702-4.

71. Stokes MB, Chawla H, Brody RI, Kumar A, Gertner R, Goldfarb DS, et al. Immune complex glomerulonephritis in patients coinfected with human immunodeficiency virus and hepatitis C virus. Am J Kidney Dis. 1997;29(4):514-25.

72. Cheng J-T, Anderson HL, Markowitz GS, Appel GB, Pogue VA, D'agati VD. Hepatitis $C$ virus-associated glomerular disease in patients with human immunodeficiency virus coinfection. J Am Soc Nephrol. 1999;10(7):1566-74.

73. Mohan S, Herlitz LC, Tan J, Cheng J-T, Anderson HL, Stokes MB, et al. The changing pattern of glomerular disease in HIV and hepatitis C coinfected patients in the era of HAART. Clin Nephrol. 2013;79(4):285-91.

74. Booth JW, Hamzah L, Jose S, Horsfield C, O'Donnell P, McAdoo S, et al. Clinical characteristics and outcomes of HIV-associated immune complex kidney disease. Nephrol Dial Transplant. 2016;31(12):2099-107.

75. Bertoldi A, De Crignis E, Miserocchi A, Bon I, Musumeci G, Longo S, et al. HIV and kidney: a dangerous liaison. New Microbiol. 2017:40(1):1-10.

76. Zafrani L, Coppo P, Dettwiler S, Molinier-Frenkel V, Agbalika F, GuiardSchmid J-B, et al. Nephropathy associated with the diffuse infiltrative lymphocytosis syndrome. Kidney Int. 2007;72(2):219-24.

77. Yoo J, Baumstein D, Kuppachi S, Singh A, Chander PN. Diffuse infiltrative lymphocytosis syndrome presenting as reversible acute kidney injury associated with Gram-negative bacterial infection in patients with newly diagnosed HIV infection. Am J Kidney Dis. 2011;57(5):752-5.

78. Martin-Blondel G, Debard A, Laurent C, Pugnet G, Modesto A, Massip P, et al. Mycobacterial-immune reconstitution inflammatory syndrome: a cause of acute interstitial nephritis during HIV infection. Nephrol Dial Transplant. 2011;26(7):2403-6.

79. Chow FC, editor HIV infection, vascular disease, and stroke. Seminars in Neurology. Thieme Medical Publishers; 2014

80. Gutierrez J, Albuquerque ALA, Falzon L. HIV infection as vascular risk: a systematic review of the literature and meta-analysis. PLOS ONE. 2017;12(5):e0176686.
81. Cuende JI, Saltijeral A, Estrada V, De Pérez Isla L. Vascular age calculation and equivalent risk factors in HIV-infected patients obtained from the D: A: D risk equation. Eur J Prev Cardiol. 2016;23(17):1903-8.

82. Idris NS, Grobbee DE, Burgner D, Cheung MM, Kurniati N, Uiterwaal CS. Effects of paediatric HIV infection on childhood vasculature. Eur Heart J. 2016;37(48):3610-6.

83. del Arco A, Martinez MA, Peña JM, Gamallo C, González JJ, Barbado FJ et al. Thrombotic thrombocytopenic purpura associated with human immunodeficiency virus infection: demonstration of p24 antigen in endothelial cells. Clin Infect Dis. 1993;17(3):360-3.

84. Rarick MU, Espina B, Mocharnuk R, Trilling Y, Levine AM. Thrombotic thrombocytopenic purpura in patients with human immunodeficiency virus infection: a report of three cases and review of the literature. Am J Hematol. 1992:40(2):103-9.

85. Bagheri Amiri F, Mostafavi E, Mirzazadeh A. HIV, HBV and HCV coinfection prevalence in Iran - a systematic review and meta-analysis. PLoS ONE. 2016;11(3):e0151946.

86. di Belgiojoso GB, Ferrario F, Landriani N. Virus-related glomerular diseases: histological and clinical aspects. J Nephrol. 2002;15(5):469-79.

87. Kupin WL. Viral-associated GN: hepatitis C and HIV. Clin J Am Soc Nephrol. 2017;12(8):1337-42.

88. Schlabe S, Rockstroh JK. Advances in the treatment of HIV/HCV coinfection in adults. Expert Opin Pharmacother. 2018;19(1):49-64.

89. Wyatt CM. Kidney disease and HIV infection. Topics Antiviral Med. 2017;25(1):13.

90. Moosa M, Van der Walt I, Naicker S, Meyers A. Important causes of chronic kidney disease in South Africa. S Afr Med J. 2015;105(4):320-7.

91. Post FA. Managing chronic kidney disease in the older adults living with HIV. Curr Opin Infect Dis. 2017;30(1):4-11.

92. Nix LM, Tien PC. Metabolic syndrome, diabetes, and cardiovascular risk in HIV. Current HIV/AIDS Rep. 2014;11(3):271-8.

93. Heron JE, Norman SM, Yoo J, Lembke K, O'Connor CC, Weston CE, et al. The prevalence and risk of non-infectious comorbidities in HIV-infected and non-HIV infected men attending general practice in Australia. PLoS ONE. 2019:14(10):e0223224.

94. Duncan AD, Goff LM, Peters BS. Type 2 diabetes prevalence and its risk factors in HIV: a cross-sectional study. PloS ONE. 2018;13(3):e0194199. https://doi.org/10.1371/journal.pone.0194199.

95. Mallipattu SK, Liu R, Zhong Y, Chen EY, D'agati V, Kaufman L, et al. Expression of HIV transgene aggravates kidney injury in diabetic mice. Kidney Int. 2013;83(4):626-34.

96. Kavishe B, Biraro S, Baisley K, Vanobberghen F, Kapiga S, Munderi P, et al. High prevalence of hypertension and of risk factors for non-communicable diseases (NCDs): a population based cross-sectional survey of NCDS and HIV infection in Northwestern Tanzania and Southern Uganda. BMC Med. 2015;13:126.

97. Duffy M, Ojikutu B, Andrian S, Sohng E, Minior T, Hirschhorn LR. Non-communicable diseases and HIV care and treatment: models of integrated service delivery. Trop Med Int Health. 2017;22(8):926-37.

98. Cooper V, Clatworthy J, Youssef E, Llewellyn C, Miners A, Lagarde M, et al. Which aspects of health care are most valued by people living with HIV in high-income countries? A systematic review. BMC Health Serv Res. 2016;16(1):677.

99. Chan DJ, Furner V, Smith DE, Dronavalli M, Bopage RI, Post JJ, et al. NonAIDS complexity amongst patients living with HIV in Sydney: risk factors and health outcomes. AIDS Res Therapy. 2018;15(1):6.

100. Bassett IV, Coleman SM, Giddy J, Bogart LM, Chaisson CE, Ross D, et al. Barriers to care and 1-year mortality among newly diagnosed HIVinfected people in Durban, South Africa. J Acquir Immune Defic Syndr (1999). 2017:74(4):432.

101. Ryom L, Mocroft A, Lundgren J. HIV therapies and the kidney: some good, some not so good? Curr HIV/AIDS Rep. 2012;9(2):111-20.

102. Acquah $R$, Graham $H$, Winter A. Quantifying polypharmacy in a large HIV-infected cohort. HIV Med. 2015;16(9):583-4.

103. Bastida C, Grau A, Márquez M, Tuset M, De Lazzari E, Martínez E, et al. Polypharmacy and potential drug-drug interactions in an HIV-infected elderly population Polifarmacia e interacciones farmacológicas potenciales en una población envejecida con infección por el VIH. Farm Hosp. 2017:41(5):618-24.

104. Mayne ES, George JA. Mortal allies: human immunodeficiency virus and noncommunicable diseases. Curr Opin HIV AIDS. 2017;12(2):148-56. 
105. Achhra AC, Nugent M, Mocroft A, Ryom L, Wyatt CM. Chronic kidney disease and antiretroviral therapy in HIV-positive individuals: recent developments. Curr HIV/AIDS Rep. 2016;13(3):149-57.

106. Forni L, Darmon M, Ostermann M, Oudemans-van Straaten H, Pettilä V, Prowle J, et al. Renal recovery after acute kidney injury. Intens Care Med. 2017;43(6):855-66.

107. Zaidan M, Lescure F-X, Brochériou I, Dettwiler S, Guiard-Schmid J-B, Pacanowski J, et al. Tubulointerstitial nephropathies in HIV-infected patients over the past 15 years: a clinico-pathological study. Clin J Am Soc Nephrol. 2013;8(6):930-8.

108. Woodward C, Hall A, Williams I, Madge S, Copas A, Nair D, et al. Tenofovir-associated renal and bone toxicity. HIV Med. 2009;10(8):482-7.

109. Hamzah L, Jose S, Booth J, Hegazi A, Rayment M, Bailey A, et al. Treatment-limiting renal tubulopathy in patients treated with tenofovir disoproxil fumarate. J Infect. 2017;74(5):492-500.

110. Mocroft A, Lundgren JD, Ross M, Fux CA, Reiss P, Moranne O, et al. Cumulative and current exposure to potentially nephrotoxic antiretrovirals and development of chronic kidney disease in HIV-positive individuals with a normal baseline estimated glomerular filtration rate: a prospective international cohort study. Lancet HIV. 2016;3(1):e23-32.

111. Hall AM, Hendry BM, Nitsch D, Connolly JO. Tenofovir-associated kidney toxicity in HIV-infected patients: a review of the evidence. Am J Kidney Dis. 2011;57(5):773-80.

112. Milian L, Peris JE, Gandia P, Andujar I, Pallardo L, Gorriz JL, et al. Tenofovir-induced toxicity in renal proximal tubular epithelial cells: involvement of mitochondria. AIDS. 2017;31(12):1679-84

113. Chan L, Asriel B, Eaton EF, Wyatt CM. Potential kidney toxicity from the antiviral drug tenofovir: new indications, new formulations, and a new prodrug. Curr Opin Nephrol Hypertens. 2018;27(2):102-12.

114. Flandre P, Pugliese $P$, Cuzin L, Bagnis Cl, Tack I, Cabié A, et al. Risk factors of chronic kidney disease in HIV-infected patients. Clin J Am Soc Nephrol. 2011;6(7):1700-7.

115. Scherzer R, Estrella M, LiY, Choi Al, Deeks SG, Grunfeld C, et al. Association of tenofovir exposure with kidney disease risk in HIV infection. AIDS. 2012;26(7):867-75.

116. Mocroft A, Lundgren J, Ross M, Fux C, Reiss P, Moranne O, et al. Data Collection on Adverse events of Anti-HIV Drugs (D: A: D) Study. Cumulative and current exposure to potentially nephrotoxic antiretrovirals and development of chronic kidney disease in HIV-positive individuals with a normal baseline estimated glomerular filtration rate: a prospective international cohort study. Lancet HIV. 2016;3(1):23-32.

117. The U.S. Food and Drug Administration. FDA approves first medication to reduce HIV risk. https://www.fda.gov/ForConsumers/ConsumerUp dates/ucm311821.html. Accessed 20 Nov 2019.

118. Molina JM, Charreau I, Spire B, Cotte L, Chas J, Capitant C, et al. Efficacy, safety, and effect on sexual behaviour of on-demand pre-exposure prophylaxis for HIV in men who have sex with men: an observational cohort study. Lancet HIV. 2017;4(9):e402-10.

119. Noret M, Balavoine S, Pintado C, Siguier M, Brun A, Bauer R, et al. Daily or on-demand oral tenofovir disoproxil fumarate/emtricitabine for HIV pre-exposure prophylaxis: experience from a hospital-based clinic in France. AIDS. 2018;32(15):2161-9.

120. Tetteh RA, Yankey BA, Nartey ET, Lartey M, Leufkens HG, Dodoo AN. Pre-exposure prophylaxis for HIV prevention: safety concerns. Drug Saf. 2017:40(4):273-83.

121. Pilkington V, Hill A, Hughes S, Nwokolo N, Pozniak A. How safe is TDF/FTC as PrEP? A systematic review and meta-analysis of the risk of adverse events in 13 randomised trials of PrEP. J Virus Erad. 2018;4(4):215-24

122. Coelho LE, Torres TS, Veloso VG, Landovitz RJ, Grinsztejn B. Pre-exposure prophylaxis 2.0: new drugs and technologies in the pipeline. Lancet HIV. 2019;6(11):e788-99.

123. Aloy B, Tazi I, Bagnis Cl, Gauthier M, Janus N, Launay-Vacher V, et al. Is tenofovir alafenamide safer than tenofovir disoproxil fumarate for the kidneys? AIDS Rev. 2016;18(4):184-92.

124. Novick TK, Choi MJ, Rosenberg AZ, McMahon BA, Fine D, Atta MG Tenofovir alafenamide nephrotoxicity in an HIV-positive patient: a case report. Medicine. 2017;96(36):e8046. https://doi.org/10.1097/md.00000 00000008046

125. Bahr NC, Yarlagadda SG. Fanconi syndrome and tenofovir alafenamide: a case report. Ann Intern Med. 2019;170(11):814-5.
126. Post FA, Tebas P Clarke A Cotte L, Short WR, Abram ME, et al. Brief report: switching to tenofovir alafenamide, coformulated with elvitegravir, cobicistat, and emtricitabine, in HIV-infected adults with renal impairment: 96-week results from a single-arm, multicenter, open-label phase 3 study. J Acquir Immune Defic Syndr (1999). 2017;74(2):180.

127. Burgos J, Ribera E, Falco V. Antiretroviral therapy in advanced HIV disease: which is the best regimen? AIDS reviews. 2018;20(1):3-13.

128. McLaughlin MM, Guerrero AJ, Merker A. Renal effects of non-tenofovir antiretroviral therapy in patients living with HIV. Drugs Context. 2018;7:212519.

129. Bagnis $\mathrm{Cl}$, Stellbrink H-J. Protease inhibitors and renal function in patients with HIV infection: a systematic review. Infect Dis Therapy. 2015:4(1):15-50.

130. Milburn J, Jones R, Levy JB. Renal effects of novel antiretroviral drugs. Nephrol Dial Transplant. 2016;32(3):434-9.

131. Stricker R, Goldberg B. Weight gain associated with protease inhibitor therapy in HIV-infected patients. Res Virol. 1998;149(2):123-6.

132. Deeks ED. Cobicistat: a review of its use as a pharmacokinetic enhancer of atazanavir and darunavir in patients with HIV-1 infection. Drugs. 2014;74(2):195-206

133. Spagnuolo V, Castagna A, Lazzarin A. Bictegravir. Current opinion in HIV and AIDS. 2018;13(4):326-33.

134. Wood BR. Do integrase inhibitors cause weight gain? Clin Infect Dis. 2019. https://doi.org/10.1093/cid/ciz410.

135. Yin J, Wang J. Renal drug transporters and their significance in drugdrug interactions. Acta Pharm Sin B. 2016;6(5):363-73.

136. Raffi F, Rachlis A, Stellbrink H-J, Hardy WD, Torti C, Orkin C, et al. Oncedaily dolutegravir versus raltegravir in antiretroviral-naive adults with HIV-1 infection: 48 week results from the randomised, double-blind, non-inferiority SPRING-2 study. Lancet. 2013;381(9868):735-43.

137. Shahmanesh M, Schultze A, Burns F, Kirk O, Lundgren J, Mussini C et al. The cardiovascular risk management for people living with HIV in Europe: how well are we doing? AIDS. 2016;30(16):2505-18.

138. Vassalotti JA, Winston JA. CKD in HIV-infected patients: from the new plague to chronic care management. Am J Kidney Dis. 2015;65(6):823-5

139. Wang K, Hu J, Luo T, Wang Y, Yang S, Qing H, et al. Effects of angiotensinconverting enzyme inhibitors and angiotensin ii receptor blockers on all-cause mortality and renal outcomes in patients with diabetes and albuminuria: a systematic review and meta-analysis. Kidney Blood Press Res. 2018;43(3):768-79.

140. Carey RM, Whelton PK. Prevention, detection, evaluation, and management of high blood pressure in adults: synopsis of the 2017 American College of Cardiology/American Heart Association Hypertension Guideline. Ann Intern Med. 2018;168(5):351-8.

141. Greene M, Steinman MA, McNicholl IR, Valcour V. Polypharmacy, drugdrug interactions, and potentially inappropriate medications in older adults with human immunodeficiency virus infection. J Am Geriatr Soc. 2014:62(3):447-53.

142. Allavena C, Hanf M, Rey D, Duvivier C, BaniSadr F, Poizot-Martin I, et al. Antiretroviral exposure and comorbidities in an aging HIVinfected population: the challenge of geriatric patients. PLOS ONE. 2018:13(9):e0203895.

143. Llibre JM, Hung C-C, Brinson C, Castelli F, Girard P-M, Kahl LP, et al. Efficacy, safety, and tolerability of dolutegravir-rilpivirine for the maintenance of virological suppression in adults with HIV-1: phase 3, randomised, non-inferiority SWORD-1 and SWORD-2 studies. Lancet. 2018;391(10123):839-49.

144. Ahuja TS, Grady J, Khan S. Changing trends in the survival of dialysis patients with human immunodeficiency virus in the United States. J Am Soc Nephrol. 2002;13(7):1889-93.

145. Ahuja TS, Collinge N, Grady J, Khan S. Is dialysis modality a factor in survival of patients with ESRD and HIV-associated nephropathy? Am J Kidney Dis. 2003;41(5):1060-4.

146. Locke JE, Mehta S, Reed RD, MacLennan P, Massie A, Nellore A, et al. A national study of outcomes among HIV-infected kidney transplant recipients. J Am Soc Nephrol. 2015;26(9):2222-9.

147. Stock PG, Barin B, Murphy B, Hanto D, Diego JM, Light J, et al. Outcomes of kidney transplantation in HIV-infected recipients. N Engl J Med. 2010;363(21):2004-14. 
148. Degnan KO, Blumberg EA, editors. Human immunodeficiency virus in kidney transplantation. Seminars in nephrology. Amsterdam: Elsevier; 2016.

149. Alameddine M, Jue JS, Zheng I, Ciancio G. Challenges of kidney transplantation in HIV positive recipients. Transl Androl Urol. 2019;8(2):148.

150. Zheng X, Gong L, Xue W, Zeng S, Xu Y, Zhang Y, et al. Kidney transplant outcomes in HIV-positive patients: a systematic review and meta-analysis. AIDS Res Ther. 2019;16(1):37.

151. Alfano G, Mori G, Fontana F, Dolci G, Baisi A, Ligabue G, et al. Clinical outcome of kidney transplantation in HIV-infected recipients: a retrospective study. Int J STD AIDS. 2018;29(13):1305-15.
152. Muller E, Barday Z, Mendelson M, Kahn D. HIV-positive-to-HIVpositive kidney transplantation-results at 3 to 5 years. N Engl J Med. 2015;372(7):613-20.

\section{Publisher's Note}

Springer Nature remains neutral with regard to jurisdictional claims in published maps and institutional affiliations.
Ready to submit your research? Choose BMC and benefit from:

- fast, convenient online submission

- thorough peer review by experienced researchers in your field

- rapid publication on acceptance

- support for research data, including large and complex data types

- gold Open Access which fosters wider collaboration and increased citations

- maximum visibility for your research: over $100 \mathrm{M}$ website views per year

At BMC, research is always in progress.

Learn more biomedcentral.com/submissions 